\title{
La infancia como espacio fantasmal en la poesía de Enrique Lihn
}

\author{
The childhood like ghostly space \\ in the poetry of Enrique Lihn
}

Claudio Guerrero Valenzuela

Pontificia Universidad Católica de Chile. Santiago, Chile.

cmguerre@uc.cl

\section{RESUMEN}

Este trabajo analiza las representaciones de infancia en la obra de Enrique Lihn, teniendo como punto de partida La pieza oscura (1963) y otros textos seleccionados de su producción posterior. Desde la perspectiva de un hablante adulto que vive un presente en ruinas, caracterizado por la angustia, el fracaso amoroso y la imposibilidad de atenerse a las normas que rigen la vida social, el sujeto de estos poemas vuelve hacia una infancia que se le presenta de modo fantasmal y se sitúa en ella para encontrar una causa explicativa, pero también para situarla como un tiempo y un espacio propicio para la creación poética a través de la figura del niño anciano narcisista.

Palabras claves: Infancia, poesía, Lihn, narciso, fantasma.

\section{ABSTRACT}

This work analyzes the representations of childhood in Enrique Lihn's work, taking as a point of item The dark room (1963) and other texts selected of his later production. From the perspective of an adult speaker who lives through a present in ruins, characterized by the distress, the disappointment in love and the inability to be abided by the procedure that govern the social life, the subject of these poems returns towards the childhood that appears him in a ghostly way and places in it to find an explanatory 
reason, but also to place it as a propitious time and space for the poetical creation across the figure of the elderly child narcissist.

Keywords: Childhood, poetry, Lihn, narcissus, ghost.

Recibido: 05-10-2009. Aceptado: 15-02-2010.

\section{MODERNIDAD, POSTMODERNIDAD Y NARCISO}

T a crítica ha apuntado con certeza que La pieza oscura (2007 [1963]) _inicia la más trascendente etapa creativa de Enrique Lihn (1929-1988). De hecho, el poeta, en Conversaciones, señala que lo considera, en verdad, su primer libro (Lastra, 1980: 34). El escenario básico de este poemario es la memoria del hablante, quien oscila entre el pasado, el presente y el futuro de manera desdoblada entre un yo, un tú y un él (Foxley, 1995: 65). Esta problemática se inscribe en el contexto de una producción escritural que vivencia la modernidad críticamente. Si bien comprendemos la importancia de la narrativa y ensayística de Lihn, nos centramos en su producción poética, de por sí ya vasta y compleja.

Es indudable que La pieza oscura posiciona el tema de la infancia dentro de la obra de Lihn como ya lo estaban haciendo otros poetas de su misma generación, no sólo en Chile sino que también en otras latitudes, aunque con elementos diferenciadores ${ }^{1}$. De acuerdo al propio Lihn, esta obra contiene un conjunto de poemas trabajados entre 1956 y 1962. Con esto logró instalarse en el campo literario en contra de una poesía "poética" y a favor de una poesía "situada", es decir, en relación a una "situación" (Lastra, 1980: 29-31). En este poemario y en poemas posteriores, la "situación" gira en torno a la dificultad de reconstituir la infancia de modo armónico y la incertidumbre de la memoria y de lo real en tensión con la práctica poética, de modo similar a como lo hizo posteriormente en relación a otras temáticas dentro de su obra como el viaje y las experiencias políticas dictatoriales.

Creemos que la crítica no se ha detenido lo suficiente en la profundiza-

\footnotetext{
${ }^{1}$ Este estudio se inscribe dentro de otro mayor que analiza las representaciones de infancia en la poesía chilena a partir de los años 50 . Es indudable, también, cómo este tema fue preocupación de otros poetas hispanoamericanos más o menos de la misma edad, y tan disímiles entre sí, como Eliseo Diego y Alejandra Pizarnik. Por último, cabe señalar el emparentamiento inicial y diferenciación posterior que en lo extenso de su obra intentó establecer Lihn respecto a otras poéticas, como las de Rojas, Teillier y Parra.
} 
ción del tema de la infancia. A nuestro juicio, ésta es más que un paréntesis dentro del universo lihneano (Foxley, 1995) y más que una tematización evaluativa del lugar perdido (Nómez, 2006). Postulamos que en la obra de Lihn y especialmente a partir de La pieza oscura la infancia está relacionada a la figura del Narciso (Binns, 1998) y al lugar que debe ocupar la poesía, a la autoscopía (Llanos, 2005) y autorreflexión que lo hace verse frente a un espejo (Ostria, 2005), pero también al uso de estrategias discursivas inaugurales para su obra, que define su lugar de poeta en el mundo. Específicamente, nos encontramos con dos movimientos relacionados con las representaciones de infancia. Primero, como regresión para poder "nombrar" la infancia y, luego, como oposición al mundo de los adultos. Ambas, para saldar una deuda con un presente que se vive de modo traumático y así poder reinventarse.

Respecto al tema del narcisismo en la obra de Lihn, en general se la ha asociado a la figura del poeta y a sus características personales proyectadas en los hablantes de sus poemas. Se la relaciona con su tendencia a la autorreflexividad, a la autogratificación de la escritura y a la fascinación que sentía por realizar entrevistas, escribir sobre sí mismo y guardar y publicar las críticas literarias de otros. En resumen, un "Narciso grandilocuente, ampuloso e impositivo" (Foxley, 1995: 39), que se manifiesta a partir de la incredulidad $\mathrm{y}$ angustia postmodernas de un sujeto que no tiene fe en el mundo vacío que le ha tocado vivir, y cuya figura esencial es la de un Narciso subyugado en su cápsula de cristal (Binns, 1998: 79). Intentamos, aquí, descubrir a ese Narciso en los poemas mismos y no tanto afuera de ellos.

La crítica ha puesto especial interés en situar la poética de Lihn en el marco histórico del debate modernidad/postmodernidad. Para Foxley (1995) esta escritura tiene características propias de un sujeto descentrado dentro de la vida moderna que, sin embargo, intenta desestabilizarla desde su práctica poética, en el marco de un tiempo histórico "fragmentario, discontinuo y laberíntico, muchas veces asfixiante, siempre represivo" (335), un sujeto borrado, sí; excéntrico, sí; pero "activo" (337). Nómez (2004) señala que esta poesía, así como la de otros de una misma generación (Parra, Carlos de Rokha, Rojas, entre otros), se caracteriza por situarse en el marco de una modernidad en disolución que se vive críticamente en la urbe desde la marginalidad, la orfandad, la degradación, lo oscuro y ajeno (91). Este grupo de poetas que comparte un mismo tiempo revela, cada uno desde su propia estética, los profundos "procesos de cambio que enfrentaba la sociedad" (Nómez, 2004: 96). Villanueva (2004) hace extensiva esta característica al contexto de la poesía hispanoamericana (con Vallejo, Paz, Lezama Lima, entre otros), la que 
según él ha llegado al momento en que Lihn se inserta dentro del campo, a un estado de "notable autenticidad" a partir de ciertas pautas paradigmáticas: crítica del poder y del culto a la personalidad artística, condenación del estado de las cosas reinantes, actividad intelectual continua, incorporación de voces marginales, invitación al "vicio" de escribir desde la marginación y el humor (22). A esto habría que agregar el culto a la obra metapoética, que es en donde Lihn se destaca a nivel hispanoamericano.

Esta característica reflexiva acerca del proceso de escritura genera en Lihn, a decir de Ferrada (1996), la idea de una "metáfora crítica" que surge del cuestionamiento de lo real, como síntesis de un desastre, de una ruina de habla, y que nos remite a la inconformidad e inseguridad del proceso artístico en la vida contemporánea, a la soledad e individualismo en contradicción con la masificación y globalidad, generando a la larga en su obra un "efecto de realidad" cuyo centro es la provocación (95). Esta tarea manifiesta, por un lado, la tendencia a identificar realidad y lenguaje, a entender el lenguaje como realidad única, lo que permite evidenciar en su escritura la idea de "un padecimiento agazapado: el aprisionamiento del ser humano en sus propios expedientes discursivos" (O’Nell, 2008: 55), en algo que podríamos denominar "narcisismo discursivo", pero también, por otro lado, la recurrencia a procesos de "mutaciones disciplinarias" que incluyen diversas formas textuales como la etnografía o el diario de viaje y a un travestismo en el hablante bajo diversas máscaras en donde "el disfraz no termina de suplantar al disfrazado": el sujeto multiforme de la poesía lihneana termina siendo, en sus variantes, básicamente el mismo (Galindo, 2002: 228). En este sentido, nos parece iluminadora la idea de Correa-Díaz (1996) de considerar la escritura de Lihn como un gran Monólogo sobre la Muerte, en donde el género poesía se disuelve en otros géneros para constituirse, finalmente, como un gran diario del poeta con su muerte, una post-literatura desde un espejo oscuro que se erige a sí misma como una "regresión hacia adelante" (71). Agregaríamos: desde una cierta ancianidad hacia una cierta infancia, para mostrarse, al fin, sarcásticamente deconstruido en y por el lenguaje. Ahondamos en esto más adelante.

Si la escritura de Lihn es moderna o postmoderna no es asunto que pretendemos zanjar aquí, pero queremos mover un poco la balanza hacia un lado. Nos hace sentido las palabras de Zapata (2008) cuando señala que su marginalidad como escritor lo inscribe dentro del discurso postmoderno, porque si bien Zapata centra su análisis en la narrativa de Lihn, tiene razón cuando dice que ésta bien puede entenderse como una extensión de su poesía (26): en su conjunto las tres variantes de su producción escritural (narrativa 
marginal, poesía "situada" y pensamiento crítico reflexivo) son expresión de un referente cultural complejo que alude al fracaso del Proyecto Moderno en Occidente: su obra entera es una crítica a la modernidad. Esto hace que su máquina de escritura, como su práctica política y su posición dentro del campo literario, enfatice por un lado el presente de la escritura mientras por otro intente su "desterritorialización" a través de la transformación de la noción de literatura, entendida ésta como vaciamiento experimental en el lenguaje, de modo humorístico, bufonesco, festivo y desentimentalizado, pero por sobre todo, como trabajo y en oposición a la muerte, dos concepciones medievales de la escritura actualizadas en el contexto de una problemática universal que va más allá de la cultura chilena e hispanoamericana (38-40). Partiendo de este marco contextual esperamos aportar con una óptica nueva al estado del arte desde el espacio construido de la infancia.

\section{SITUACIÓN IRREGULAR}

El sujeto lírico de varios de los textos que conforman en su conjunto el poemario La pieza oscura da cuenta de un presente problemático, insatisfecho: una situación "irregular" que lo sitúa en un espacio marginal, descentrado. En el poema "Recuerdos de matrimonio" (Lihn, 2007: 44) el hablante señala que junto a su esposa buscaban un "subsuelo" donde vivir, sin embargo, "han llegado tarde", mientras el hablante reflexiona: "Se nos hacía tarde en todo. / Para siempre" (44). La posibilidad de tener niños resulta "nuestra última esperanza", como señala en el poema "Destiempo" (45), sin embargo, el tiempo "se nos iba pasando pobremente / y estos son, pues, los años venideros". El sujeto está, entonces, situado en un presente imposible de un compromiso formal estable y con proyecciones. Un sujeto, en definitiva, que no sabe "amar" como las normas sociales así lo establecen, en el marco de una familia nuclear, monogámica.

La sensación de estar perdido en un presente angustioso es simbolizada con aún más fuerza en el poema "Jonás" (50), cuando dice: "sólo sé que seremos destruidos" y luego, en cursivas, "Asisteme señor en tu abandono". Vemos a un sujeto que se siente emparentado con la figura bíblica: en el vientre de la ballena, en un espacio cerrado, como pieza oscura, con un destino abismal, implorante ${ }^{2}$. Pero resulta interesante agregar aquí una cosa:

\footnotetext{
${ }^{2}$ Esta historia trata de la ira divina sobre Jonás por negarse a proclamar su palabra. Jonás huye en un barco y Dios hace que una tempestad ponga en peligro a sus tripulantes, quienes al enterarse de que todo ha sido por culpa del desobediente, lo arrojan al mar. Náufrago, Jonás es tragado por
} 
la teoría psicoanalista asocia la imaginería digestiva (el vientre) como un síntoma de regresión a la fase narcisista. La necesidad narcisista primordial (Freud, 1979 [1914]) es ser amado por otro, por lo que el narcisista excesivo sufre una gran pérdida: justamente, el no ser amado por los demás. El miedo a la soledad o a la marginación hace que un sujeto de desarrollo normal supere esa etapa y se adecue a las normas sociales de convivencia. El sujeto de estos poemas, en cambio, pareciera ir al revés. De ahí, en cierto modo, su abandono.

La tendencia a medir el mundo como si fuera un espejo del yo hace que el sujeto se sienta vacío: "una sensación de estar como muerto o una incapacidad de sentir o relacionarse con los demás" (Sennet, 1980: 53). El sujeto de estos poemas pareciera no lograr superar ese vacío, generando en él otro movimiento: como señala Bachelard (1993 [1957]), "el complejo de Jonás" es la necesidad del sujeto de refugiarse en un espacio que otorga las seguridades primarias de la vida en tanto imagen de una intimidad tranquilizadora en contraposición a una exterioridad amenazante. En este sentido, el refugio circular equivale al vientre femenino. Por esto, podríamos entender esta regresión como una muestra de un excesivo narcisismo que se expresa en una insatisfacción adulta, la cual, a su vez, es una metáfora extensiva de un desacomodo como poeta en el mundo de quien busca un lugar donde instalarse dentro del campo: como señala Foxley, "lo paradójico de la figura de Jonás es que su profecía no se cumple debido a que Dios se apiada del arrepentimiento de los habitantes de esa ciudad y no los destruye, anulando con ello la efectividad del discurso del profeta. De ahí deriva que el poeta del texto sea un profeta frustrado, como Jonás" (72). Esa frustración, señala Sennet, es común en la vida moderna: lo que se espera del exterior es tan vasto que éste "se convierte en un mar sobre el cual flota el yo sin diferenciación” (54), por lo que las experiencias concretas con los demás nunca parecen suficientes. Al yo diluido sólo le queda mirarse al espejo y recluirse en el trabajo poético y su lenguaje.

El hablante de estos poemas también realiza constantes alusiones a temáticas de origen medieval que, al actualizarse en un contexto moderno, resultan no sólo muestra de un profundo conocimiento de la historia de la literatura sino que también una crítica al tiempo presente. Uno de estos tópicos es el de las etapas o edades de la vida y que de acuerdo a Ariès (1987 [1960]) tuvo continuidad popular hasta principios del s. XIX gracias a la reproducción de

un gran pez, y en su vientre pasa tres días y tres noches, "rodeado de abismo". Dentro, implora a Dios para volver a la tierra a pagar lo prometido. 
un grabado llamado Escalas de las edades. En la concepción medieval se consideraba que la vida estaba separada por edades delimitables, por ejemplo, siete edades de siete años cada una o doce edades correspondientes a los doce meses del año, entre las variantes de una idea de corresponder la vida con elementos cósmicos o biológicos. Esta idea solía ser representada a través de una pareja de personas que sube una escala y luego la descienden en una suerte de arco simétrico y en el cual, bajo el centro, como si fuere el ojo de un puente, se hallaba la muerte representada como un esqueleto con una guadaña. Esta iconografía de origen medieval remite no sólo a las danzas de la muerte (Ariés, 1987: 45) su repetición en las paredes familiares y almanaques generaba una estabilidad, un modo de concebir la existencia que iguala periodización de la vida con ciclo de la naturaleza y con la organización de la sociedad (Ariés, 1960: 46), lo que le sirve a Lihn para resaltar todo lo contrario.

La anticipación de la muerte y la visión de una existencia que se dirige irremediablemente hacia ella la encontramos, en efecto, en los dos monólogos insertos en La pieza oscura. Uno es el "Monólogo del padre con su hijo de meses" (2007: 26-29), en donde el hablante adopta la voz de un padre de tono imperativo y pedagógico que aconseja a su hijo recién nacido, niño que no escucha ni sabe lo que le dicen: "Nada se pierde con vivir, ensaya; aquí tienes un cuerpo a tu medida", para luego aventurarse a decirle cómo son las etapas de la vida; es decir, existe aquí una sensación de que no hay novedad, que todo ya se ha experienciado o está predeterminado dentro de límites reconocibles: el padre no cree que el niño podrá ser feliz cuando sea adulto, presentándolo como una proyección de sí mismo, hablándole desde una cierta ancianidad. El niño, a su vez, no puede responderle.

En el "Monólogo del viejo con la muerte" (30-32) ocurre un movimiento similar. La diferencia está en que aquí es la muerte quien habla como personaje y hace que el sujeto se mire a un espejo para decir, irónicamente: "Y bien, eso era todo", como diciendo esto era la vida. Frente al espejo (Narciso), el sujeto se ve a sí mismo en diferentes etapas: desde niño a anciano, configurándose como un sujeto que ha sido golpeado por la existencia (se señala en dos ocasiones la frase "le han pegado en la cara") y que reconoce el fracaso en la única parte del poemario que da espacio a la repetición anafórica: ella (la mujer, la muerte, imaginémosla con una guadaña) es la que le exige, la que finge, la que le espanta, la que se burla, la que amenaza, la que huye. En este poema, como en el anterior, el sujeto se da espacio para pensar la existencia y en esa reflexión,

\footnotetext{
${ }^{3}$ El propio Lihn revela a Lastra el uso intencionado de este tópico a raíz de su vinculación con La danza de la muerte (Lastra, 1980: 107).
} 
la infancia aparece como parte fundamental de un ciclo vital amenazado, desde su origen, por la muerte.

Pero estos dos poemas no pueden entenderse sin un tercero, que lo completa y lo cierra: se trata del "Monólogo del poeta con su muerte" presente en Poesía de paso (2008a [1966]). En este poema, el sujeto regresa a la niñez a través de la figura del Narciso que se ve a sí mismo cada siete años en un espejo sangriento:

Cuánta inocencia ahora

que la muerte prepara tu bautismo

en las aguas servidas de la sangre

una y mil veces transformadas en vino

quieres que tú te mires en ellas sollozando,

como si todo tu pasado fuera

algo por verse allí

en ese triste espejo que volvía a trizarse

cada siete años, con tu cara adentro.

Todo lo tuyo fue -dicen las trizaduras-

altos y bajos de la mala suerte (Lihn, 2008a: 63)

Este Poeta-Anciano-Narciso, del cual el hablante señala "te miras el ombligo del mundo", termina, como en reversa, en su infancia, en donde "no más / juega tu corazón, como en un viejo patio / casi vacío", "salvando el escollo de la noche" (la muerte) con el aire (la poesía) que le murmura al oído: "ahora estás sano y salvo". Entonces ahora el Poeta-Niño-Narciso, infante "con las orejas y las manos sucias", vuelve junto a su madre "para aventar del patio los recuerdos / turbulentos". Y en esa regresión, se vuelve Jonás.

Esa madre, como señala Kristeva (1999) es de quien el sujeto se está recién separando para configurar su identidad, puesto que el Narciso freudiano "no sabe en absoluto quién es": su imagen es inestable, fronteriza, aún demasiado dependiente del "otro" (87). Pero es, también, la madre-poesía que lo cobija y salva de la muerte. Este poema resulta clave para entender la concepción que Lihn tiene de la infancia: como un espacio de configuración de la identidad del hablante que intenta construirse, encontrar su espacio y crecer. Es ahí cuando se puede ver al espejo: al reconocer la imagen del yo, separada de la imagen de la madre (Kristeva, 1999: 100). Pero para eso debe volver atrás.

Hemos visto que la representación de la infancia en estos poemas de Lihn se cruza polifónicamente con intertextualidades literarias propias del mundo medieval. Otra recurrencia de este tipo, esta vez para dar cuenta de 
los vaivenes inevitables del tiempo y explicar, en parte, el presente ruinoso, se da con el tópico de la rueda de la fortuna, en el poema "La pieza oscura" (23-25). Cuando el hablante señala que la rueda se atasca "como si no volara", y que lo hace "con un imperceptible sonido musgoso", constatamos una sinestesia que encarna en el musgo que apenas suena un tiempo degradado que abruma, y que permite al hablante formar un paralelo entre dos generaciones: la niñez y la adultez dentro del marco de la circularidad envolvente del poema. La niñez es descrita de "ojos brillantes", en cambio la adultez es de "ojos opacos"; la rueda, en tanto, gira para una generación para adelante y para la otra para atrás ("en el sentido de las manecillas del reloj y en su contrasentido"), lo que hace que el juego de los niños que giran entre sí por el suelo también sea, de manera extrapolada, el juego de dos adultos. Se da, así, una simultaneidad temporal que permite al adulto revestir de infancia un estado actual para que sirva de contraste. Por entonces, "el tiempo volaba en la buena dirección” y avanzaba "más rápido que el reloj del comedor", es decir, era un tiempo cargado de intensidad y sentido: "volaba como para arrollarnos con un ruido de aguas espumosas", más rápido que "la rueda del molino y con alas de gorriones", ambos "símbolos del salvaje orden libre". Ahora, en cambio, el hablante (revestido en niño), tras el impulsivo juego en donde él ha mordido el cuello de su prima, cae de rodillas "como si hubiera envejecido de golpe", preso "de empalagoso pánico / como si hubiera conocido, más allá del amor en la flor de su edad, la / crueldad del corazón en el fruto del amor, la corrupción del fruto y / luego... el carozo sangriento, afiebrado y seco", como si hubiera conocido temprano, en suma, lo que es el amor y cuán rápidamente se corrompe.

El niño-adulto del poema es el que da cuenta del fin de su infancia de manera precoz. Es un niño envejecido que nos habla desde una cierta ancianidad: un puer senex medieval, tempranamente experimentador y consciente de que ya no hay vuelta atrás. Por eso este presente es un tiempo náufrago cargado de nostalgia que lo hace preguntarse: “¿Qué será de los niños que fuimos?" y constatar que cuando se entra en el tiempo "nos dispersamos para siempre, al igual que los restos de un mismo naufragio". En este juego de máscaras vemos que el hablante termina por declarar, al final del poema "La pieza oscura", que una parte suya se ha negado a girar al compás de la rueda y que es "en parte ese niño que cae de / rodillas", por lo que no ha cumplido aún toda su edad ni llegará a cumplirla como ese niño "de una sola vez y para siempre". Así, el hablante intenta desmarcarse, no reconocerse en esa niñez que rápidamente se clausuró, antes de tiempo, aunque sea él mismo el que se configura en el presente como un "fantasma", un "náufra- 
go", una fractura en esa parte de las etapas de la vida que da cuenta del paso de la niñez a la adultez.

Como señalara Lihn en sus Conversaciones, este momento "comprende la disponibilidad plena del niño para ser un adulto antes de que eso ocurra y empiece con ello un proceso de constante degradación" (Lastra, 1980: 36), una filosofía negativa de la existencia que concibe la vida como una cuenta regresiva que termina en la muerte, como lo expresa en sus "monólogos". Esta negatividad de la existencia se completa a través de su oposición "positiva”, es decir, que es posible neutralizarla "con la creencia en la creación poética como un modo de enmendar la existencia, produciéndola en otro plano, en el lenguaje" (Lastra, 1980: 37), esto es, en un espacio otro, como aparece en el "Monólogo del poeta con su muerte": junto a la madre-poesía que lo cobija en su regresión pero que lo fortalece y blinda ante lo exterior. Cuando el niño se separa de la madre producto de la adquisición del lenguaje, dice Kristeva, pasa por una fase depresiva necesaria de experimentar para poder superarla y poder recobrar el objeto perdido (la madre) a través del lenguaje, nombrándola (1999: 103). Es el proceso que el hablante de estos poemas estaría representando y que le deja el camino despejado, una vez liberado de esa ausencia, para la consolidación del yo narcisista bajo la perspectiva de poder investir en otro objeto una producción del propio yo, "que es nada menos que su propia aptitud para representarse, para significar, para hablar, para pensar" (1999: 103). El yo de un niño-adulto fracturado en algún lugar de las etapas de la vida.

Entendemos, ahora, dos de los procesos que realiza este autor a partir de La pieza oscura: el saldar una deuda con su infancia para, luego, posibilitar un posicionamiento en el campo literario chileno e hispanoamericano con un trabajo arduo del lenguaje. Sin embargo, señala Cerda, esta tarea instituye una fantasma que o bien refuerza el narcisismo primario (como en Huidobro, por ejemplo), o bien reproduce la angustia edípica, "ahora ya no dirigida a una madre inalcanzable, sino a la inmarcesible belleza poética" (2006: 144), como en la poesía de Lihn. Éste termina dimensionando el lenguaje poético y el acto de escritura como su objeto de deseo y goce, siempre problemático por ser efímero y marginal, pero también como su único espacio de verdadera diferenciación respecto a los otros.

Es por esto que el hablante de estos poemas aboga por una poesía, como dice en "Zoológico" (48), que no utiliza "un viejo lenguaje enjoyado de lugares comunes" ni una "inocente canción sin asunto" que cualquiera podría aprender fácilmente, una poesía que "no vuelve con las hojas", aludiendo con todo esto a la tradición poética anterior, sino que una poesía 
que "florece en el destierro", en el ensimismamiento de una "serpiente", como se define a sí mismo, "casi invisible en su celda de vidrio, en el rincón más / sombrío del parque", y cuyo veneno es el lenguaje que lo mantiene "ajena a los intereses de la / tierra". Esa poesía encarnada en una serpiente no es más que la imagen del Poeta-Niño (envejecido)-Narciso en la cápsula de cristal postmoderna: "yo soy ese insensible amante de sí mismo que duerme con astucia, mientras / todo despierta". Un puer senex experimentador, astuto, enmascarado, que bien responde a las características del niño de la vida moderna, a decir de Janer (2005): “ávido de pasión, turbulento, dispuesto a rechazar todos los límites, abierto a la fantasía, constantemente dispuesto a inventarse el mundo, a disfrazarse y a ponerse todas las máscaras, a crecer de manera desordenada y loca, a buscarse a sí mismo entre los pliegues del espejo" (767). Un niño anciano que experimenta el mundo para construir una poesía, como señala el hablante de "Ciudades" en Poesía de paso, incómoda: "En el gran mundo como en una jaula / afino un instrumento peligroso" (24). Una poesía como un "gran fantasma bobo" del poema "Mester de juglaría" (21-25) de La musiquilla de las pobres esferas (2008b [1969]), y que lo vuelve un "extranjero" como dice en el poema "Porque escribí". Sin embargo, es lo que le permite estar vivo: "porque escribí porque escribí estoy vivo" (66-68). Regresar a la infancia es otra manera de estar vivo.

\section{UN ESPACIO FANTASMAL}

La zona muda, dice Lihn en su poema "Nada tiene que ver el dolor con el dolor" (13) en Diario de muerte (1989a), es el lugar donde "no hay nombres", es "esa cosa muerta que existe en el lenguaje y que es / su presupuesto", "una palabra viciada". Polanco (2004) señala que esta zona callada es un "agujero negro" que envuelve y atrapa la imagen que el poeta tiene de sí mismo: un trabajador precario cuyo objeto de trabajo, las palabras, son precarias y que se pierden, inexorablemente, en la muerte. Por eso, "el vicio de la palabra es la gran barrera que el poeta nunca podrá cruzar" (186), la palabra es "una pérdida", una "letra moribunda" porque "no aprehende cabalmente la realidad en que se suscitó" (186). Creemos que este autor se acerca a un asunto aún más profundo relacionado con la infancia.

Recordemos que, etimológicamente, infancia significa "mudez", el que no "puede hablar", por lo que, como señala Agamben (2007 [1978]), la mudez es experiencia pura: "Una experiencia originaria, lejos de ser algo 
subjetivo, no podría ser entonces sino aquello que en el hombre está antes del sujeto, es decir, antes del lenguaje: una experiencia 'muda' en el sentido literal del término, una in-fancia del hombre, cuyo límite justamente el lenguaje debería señalar" (Agamben, 2007: 64). Esto hace que entendamos la zona muda como el lugar de la infancia, aquello que no se puede nombrar sin averiarla. La poesía de Lihn es un intento angustioso por volver a nombrarla. De ahí que la insistencia por un espacio otro se vuelva una instancia trágica, cuya única realización pueda ser el lenguaje gastado, del Narciso anciano, en esa zona donde la muerte espera "a sus nuevos amantes" (Lihn, 1989a: 13), es decir, a los acólitos de la escritura.

Recurrir al pasado, señala Benjamin (2006 [1950]) significa "excavar en la memoria", es decir, un medio para descubrir en el pasado algo que explique parte del presente. Sin embargo, dice el autor alemán, quien recurre al pasado encontrará una serie de profundas capas o estratos de pasado, como un tesoro de imágenes que muestra, a la larga, el carácter palimpséstico de la memoria, esto es, su capacidad de conservar las huellas de una escritura anterior borrada artificialmente. Esto hace que el mundo de la infancia sea un mundo inaccesible y que su mitología esté destinada a disolverse en el espacio de la historia. Por lo tanto, la recurrencia a sus más oscuros "recreos" sólo puede ser posible a través de la apropiación de las energías inconmensurables del sueño, es volver al "sueño del pasado" (15). Creemos que este procedimiento es el que utiliza Lihn para brindarnos un "sueño" de la infancia, un espacio mudo cuya experiencia se acaba con la intervención de un lenguaje torpe que intenta asirla, cuando en verdad ya se ha ido, dejando al sujeto de sus poemas en un presente angustioso ante la intuición de que la poesía es un oficio que si bien lo mantiene vivo, lo deja en un estado de precariedad existencial, en su jaula de vidrio, frente a la muerte.

En el poema "La pieza oscura", dice Lihn, el sujeto da cuenta "de la imposibilidad de reconstituir en sí misma la infancia: es la memoria la que la está produciendo a la par con el lenguaje poético, actividades que se identifican. La infancia es lo que solo existe gracias a la memoria en el presente del texto" (Lastra, 1980: 35). Y en el "Prólogo (a versos y años)" de su antología publicada en España Album de toda especie de poemas (1989b) señala que en este poema, "el país extranjero es la infancia; el visitante, la memoria; y donde esos electrodos brota, en el lenguaje, la fantasmagoría que se refleja en él; pues el lenguaje es, también, un fantasma, y, el poema, una materialización” (Lihn, 1997: 411). Apreciamos cuán lúcido se muestra Lihn para determinar su idea sobre las relaciones entre infancia y poesía. La infancia es "posterior" a la poesía, porque sólo puede ser nombrada a partir de ella: 
Infancia y poesía están asociadas por el principio de la casualidad y la lógica de la indeterminación. La segunda debiera ser el efecto de la primera, pero está la ley de las excepciones. Según ésta, como la infancia es una consecuencia de la poesía, habría una ancianidad previa al acto poético (Lihn, 1997: 412).

Volvemos, entonces, a los poemas donde la infancia intenta ser nombrada y descubrimos nuevos elementos que discutir. Vimos que "La pieza oscura" (23-25) presenta dos mundos que se oponen: el mundo de los adultos que se diferencia de manera radical al de los niños. Llanos recuerda en una conferencia titulada "Hacia Enrique Lihn" que "antiguamente, cuando los niños se portaban mal, se los castigaba encerrándolos un rato en una pieza oscura, que solía ser el espacio más ingrato de la casa" (Llanos, 2005: 51). En efecto, en este poema el espacio que se describe parece más un lugar de castigo que una pieza de juegos, con frazadas que se confunden "unas con otras a modo de nidos como celdas, de celdas como / abrazos, de abrazos como grillos en los pies y en las manos". En este texto, los dos niños tienen la nariz sucia, "símbolo de inocencia y de precocidad" y juegan en un inocente secreto "por no sabíamos no / ignorábamos qué causa" con sus primas. Todos, son "villanos, pero igualmente dulces". En el juego, los niños ruedan de dos en dos "con las orejas rojas -símbolos del pudor que saborea su / ofensa- rabiosamente tiernos" y uno de ellos muerde en el cuello a su prima Isabel. Su primo Ángel, en tanto, ha vencido a Paulina. Después de girar por el suelo, las niñas son "ninfas en un capullo de frazadas" y estornudan por el "olor a naftalina en la pelusa del fruto", como si ellas también hubiesen envejecido. Cuando todo se acaba, los niños tienen tiempo para encender la luz sabiendo que eran buscados por los adultos. Como señala Llanos, la exploración sexual inconsciente que realizan los niños se manifiesta como "pulsiones nacientes" que oscilan "entre la culpa y la osadía, entre el pudor y la fascinación, entre el descubrimiento del otro y el autodescubrimiento" (Llanos, 2005: 51). Se revela aquí la distancia existente entre los dos mundos, que contraponen aventura y orden; deseo y ley; ello y superyó, como la conciencia que tienen los infantes de su condición: saben que ellos son vistos como "ángeles"; los adultos, en cambio, son "sempiternos cazadores de niños". De esta manera, cuando los adultos entran a la pieza, los niños ojean revistas ilustradas, ellos en un extremo, ellas en el otro, "en un orden perfecto, anterior a la sangre". Aquí, los niños están marcados por una precocidad iniciática que hace que hayan cumplido toda su edad "de una sola vez y para siempre", interiorizando la represión que los adultos ya no necesitan ejercer. 
La oposición adulto/niño, sin embargo, se exacerba aún más en otros tres poemas que forman un tríptico: "Invernadero", "Navidad" y "El bosque en el jardín”. En el primero (36-37) aparece un sujeto que comienza y termina el poema preguntándose: “QQué será de nosotros, ahora?” y si la noche los sorprendió en el bosque o si reencontraron "el buen camino familiar" y se les hizo tarde junto al invernadero. La ambigüedad planteada revela la distancia tensa existente entre los dos mundos: por una parte, da cuenta de la custodia de los niños sobre los cuales no se repara sino "bien entrada la noche", de manera "agridulce"; pero, por otro lado, plantea, también, a un hablante que duda del verdadero conocimiento del bosque, es decir, si se ha tratado de una experiencia real o soñada. En este poema hay dos escenarios que se contraponen: el invernadero que aparece simbolizado como el lugar donde transcurren los sueños de infancia, pero de manera acotada, por decirlo así, con el permiso de los adultos; y el "bosque inexpugnable" que es el espacio que está más allá de una frontera imaginaria y que simboliza la libertad total, donde los adultos no mandan ${ }^{4}$. El sujeto se sitúa entre dos opciones: quedarse en el espacio del invernadero, armónicamente, junto al orden familiar, o perderse en el bosque con el encanto de la libertad.

En el segundo poema (38), el sujeto lírico declara que la niñez ha sido destronada por los cardos. Estos, sabemos, son flores espinudas que pueden provocar heridas; en este poema hay, entonces, una mirada hacia la infancia como un tiempo que ha sido dolorosamente dejado atrás para formar parte del mundo de los adultos: los niños son "fantasmas perdidos" que buscan infructuosamente "una calle en el desierto". Aquí, la infancia es vista como desde un duelo: es necesario identificar los despojos y localizar a los muertos. En esta tarea de identificación de los restos, se comienza a vivir, verdaderamente, una nueva etapa. Sin embargo, si no es posible cerrar el ciclo, estos restos aparecen como "fantasmas", signos de una niñez inacabada. Como afirma Derrida (2002 [1995]): "un espectro es siempre un (re)aparecido" (27), un fantasma que asedia, que siempre está por aparecer y reaparecer, que no muere jamás, que hace mover los signos (146). Su venida, su visita, provoca que el sujeto deba desarrollar una rearticulación del tiempo presente en cuanto se vivencia como experiencia de algo inacabado, un desajuste,

${ }^{4}$ El jardín y el bosque forman parte del imaginario de lo íntimo, pero entre ambos hay una leve aunque sustantiva diferencia: el bosque, con su paisaje cerrado, es constitutivo del lugar sagrado, es una cosmización más amplia que el microcosmos de la morada, arquetipo de la intimidad feminoide (Durand, 2006: 254). Lo mismo señala Bachelard al afirmar que el bosque, con su misterio de espacio indefinidamente prolongado, constituye una simbolización de una "inmensidad interior" (Bachelard, 1993: 222). Del mismo modo, nótese el viaje que realiza el niño para llegar al bosque: esa travesía está cargada de un simbolismo que lo aleja de lo "familiar". 
un trauma y que se vive en este caso como revuelta: crisis que necesita ser rearticulada a partir de la ruptura o dislocación, un situarse en otro lugar; un lugar oponible a desierto, a matrimonio, a la vida normal, un lugar que bien puede ser el bosque, la infancia, la creación poética.

En el poema que cierra esta tríada (39), el hablante lírico vuelve a preguntar: “QQué será de nosotros...?” y señala que fueron obligados a prometer que nunca repetirían la acción de ir al bosque. La aventura es personificada como una mujer seductora "que todo lo había tomado de nosotros", ligándolos a su destino, pero que sin embargo, por culpa de los padres, los abandonaba "a la miseria" del esperado por todos (la familia, la sociedad) para ellos. Así, casi con rencor, señala que "nuestros padres nos reservaron un despertar olvidadizo", agregamos: un despertar sin memoria, un despertar mudo: "El pozo fue cegado / y en el camino de la selva se levantaba una tapia; en un jardín como otros, / nada que recordara / la migración de los pequeños salvajes". De pronto, entonces, se traza una frontera y la infancia es clausurada de manera violenta: el pozo es "cegado" como antes fue iluminada la pieza oscura y se levanta un muro para mantener el control. Resulta coherente, entonces, que el sujeto dé cuenta, a través de un pozo que ha sido "cegado", de una adultez que ciegamente intenta adueñarse de la infancia y que convierte a los niños en unos "atolondrados actores". Nótese aquí la polisemia del término "cegar": no sólo cerrar o macizar algo que antes estaba hueco, sino que también: 1. quitar la vista, 2. turbar la razón.

Estos huéspedes silenciosos de un hogar que no les pertenece como señalara Benjamin (1989) son los niños cuyo universo de reglas propias se contrapone al de los adultos. Sin embargo, el niño está obligado a someterse a este espacio ajeno, haciendo de él "un huésped errante e inseguro" (Benjamin, 1989: 98). De esta manera, los niños en el poema de Lihn son "los ausentes", son "una especie de fantasmas / pero de esos que nadie invocaría", son los "pequeños salvajes" migratorios que terminan siendo apartados por los adultos, quienes imponen las condiciones y normas de vida. La infancia, por tanto, es revivida mediante su conjura, como una invocación de esos huéspedes: los fantasmas "siempre están allí, en su lugar / esperando el momento de aparecer en escena, solo por un momento que / nadie les disputa / y que nadie quisiera disputarles" (39). La infancia en Lihn es doblemente fantasmal: no sólo se le aparecen al sujeto adulto que construye los poemas, motivando la escritura, sino que ellos mismos son revividos y representados como fantasmas.

El tema de los niños como reos en un hogar que no les pertenece vuelve a aparecer en el poema "Episodio" (41) bajo la tentación de la huida para dar 
fin al confinamiento. Sin embargo, el sujeto confiesa: "No me resolví nunca a abandonar la casa en el momento oportuno. / Del otro lado del cerco se me hicieron las señales convenidas". Todo queda igual y de esa manera los adultos "se abstuvieron ya de razonar y de advertir / hundiéndose en el polvo victorioso, con la cabeza pesada". El niño es disciplinado y obligado a vivir bajo los códigos adultocéntricos hasta que pueda valerse por sí mismo, aunque ya ha anunciado que afuera alguien o algo lo llama: el comienzo de otra etapa, la promesa de un oficio con la palabra. El disciplinamiento, sin embargo, es recordado otra vez de manera rencorosa, irónica y dramáticamente expresado en el poema "Bella época" presente en Poesía de paso, para cerrar esta oposición adulto/niño:

Los que vivimos en la ignorancia de la personas mayores sumada a nuestra propia ignorancia (...)

Sí, verdaderamente hijos de la buena voluntad, del más cálido y riguroso estoicismo. Pero, ¿̨no es esto una prueba de amor, el reconocimiento del dolor silencioso que nos envuelve a todos? (...)

Los que habíamos aprendido a entrar en puntillas al salón de la abuela materna; a no movernos demasiado, a guardar un silencio reverente (...)

huéspedes respetuosos y respetados a los seis años (...) oprimidos en el corazón. Adelgazados en la sangre. Caldeados en el aliento (Lihn, 2008a: 35-38).

Nos situamos aquí, entonces, delante de una descripción de un niñoadulto que vive como fantasma, un tiempo y un espacio para nada "bello" sino que más bien "oscuro" como la pieza y el vientre de la ballena; y que le hace decir al hablante del poema "Bosque" (38), en Una nota estridente (2006), que "bien podría anunciar el nacimiento de un poema / feliz que ojalá fuera éste". Aquí, donde el hablante señala que "de la lengua escapan las palabras que la acosan", plantea el anhelo de querer volver a ese bosque "inexpugnable", aquello que hemos postulado como la infancia muda anterior al lenguaje: el sonido de un "poema imposible / tan parecido a la felicidad". Dice al final de éste:

Semejante oscuridad bien podría anunciar el nacimiento de un poema feliz que ojalá fuera éste.

Ojalá, ojalá. Quiero volver al bosque, 
mis palabras me llenan: voces que debo interpretar: un canto como de hojas, anterior al lenguaje,

la esperanza, a través de los árboles, de encontrarse en la perla del bosque con una "luz no usada" que lo ilumine todo en el espacio de un instante de siempre,

y olvidando el lenguaje que repta, abrir el corazón al canto que lo colma. El corazón: la boca del poema imposible

tan parecido a la felicidad (Lihn, 2006: 38).

Postulamos que esa oscuridad es la infancia que pretende ser iluminada, a posteriori, desde una ancianidad traumática, por un lenguaje no usado. La infancia es esa zona muda que intenta ser nombrada como una forma de compensación. Pero el Poeta-Narciso, el niño envejecido, sabe que eso resulta una tarea difícil con un lenguaje apenas restituible. En ese intento escritural, sin embargo, vive, precariamente, pero vive frente al mundo que se desmorona a su alrededor.

\section{UNA ESTRIDENCIA FINAL A MODO DE CONCLUSIÓN}

La infancia en esta poesía se sitúa entre dos mundos: los niños son representados como los invitados, los ausentes, los fantasmas, los pequeños salvajes, los precoces. Los adultos, en cambio, son los cazadores de niños y ejercen coerción sobre ellos. Estos niños, además, se mueven en espacios asfixiantes y amenazantes: piezas, pozos, muros, cardos, desiertos; en definitiva, son pequeños y ajenos huéspedes en un mundo cargado de una grave adultez que no se arregla con el modo de vivir normal. Recurriendo a tópicos de origen medieval, la presencia de estos niños-fantasmas termina siendo consecuencia y signo de un asedio, por lo que se los invoca para "hacerles justicia" (Derrida, 2002: 251); su conjura, en consecuencia, es una posibilidad de vivir, de otra manera, en un nuevo ciclo, para cerrar un presente en deuda. Ese nuevo vivir es la decisión de intentar hacer poesía a partir de La pieza oscura con aquello que el lenguaje no nombra sino "viciadamente", por lo que esta posibilidad es el consuelo y aparataje de tintes postmodernos para reparar una experiencia traumática de la vida moderna que va a acompañar al hablante de los poemas de Lihn a lo largo de toda su obra con diferentes máscaras (Narciso, mendigo, Pompier, etc.). Es así como el Poeta-NiñoNarciso de estos poemas, el puer senex enmascarado que nos habla desde una cierta ancianidad, vuelve a aparecer en la última obra lihneana, en Diario 
de muerte, como el bebé "mezcla de sapo y ángel" (65) que se posa sobre el pecho de "la mujer reemplazada en Klinger por una estatua yacente" $(65)^{5}$, para mirarnos burlonamente a nosotros, los lectores, con su rostro de niñoadulto "como en un teatro / donde se representa una obra congelada" (65). Esa obra congelada, fantasmal, es el abismo final de una poética que se aferra, hasta el último instante, narcisista, irónico y dramático, a su pequeño espacio de creación delante del terrible espectáculo de la muerte.

\section{REFERENCIAS}

Agamben, Giorgio. 2007 [1978]. Infancia e historia. Buenos Aires: Adriana Hidalgo ed., 222 pp.

Ariès, Philippe. 1987 [1960]. El niño y la vida familiar en el antiguo régimen. Madrid: Taurus, $548 \mathrm{pp}$.

Bachelard, Gastón. 1993 [1957]. La poética del espacio. FCE: México, 283 pp.

Benjamin, Walter. 1989 [1969]. Escritos. La literatura infantil, los niños y los jóvenes. Buenos Aires: Nueva Visión, 142 pp. 2006 [1950]. Berlin Childhood around 1900. Cambridge (EEUU): Harvard University Press, 192 pp.

Binns, Niall. 1998. "El narcisismo en Enrique Lihn: autorreflexividad en el amor y en la poesía" en Taller de Letras 26, pp. 69-84.

Cerda, Kristov. 2006. "Una poética desde la marginalidad y el fracaso: el escupitajo en la escudilla de Enrique Lihn" en Alpha 23, pp. 137-152.

Correa-Díaz, Luis. 1996. Lengua muerta: poesía, post-literatura y erotismo en Enrique Lihn. Providence, Rhode Island: Ediciones Inti, 115 pp.

Derrida, Jacques. 2002 [1995]. Espectros de Marx. Madrid: Editora Nacional, $252 \mathrm{pp}$.

Durand, Gilbert. 2006 [1992]. Las estructuras antropológicas del imaginario. México: FCE, 484 pp.

Ferrada, Ricardo. 1996. "Enrique Lihn o la estética de la provocación”. En Estudios Filológicos 31, pp. 81-96.

Foxley, Carmen. 1995. Enrique Lihn: escritura excéntrica y modernidad. Santiago, Universitaria, $345 \mathrm{pp}$.

Freud, Sigmund. 1979 [1914]. Estudio del narcisismo y otros ensayos. Madrid: Alianza, 159 pp.

\footnotetext{
${ }^{5}$ Se trata de un grabado de Max Klinger, Madre muerta (1889), incluido en Diario de muerte.
} 
Galindo, Oscar. 2002. "Mutaciones disciplinarias en la poesía de Enrique Lihn” en Estudios Filológicos 37, pp. 225-240.

Janer, Gabriel. 2005. "La invención literaria de la infancia: del niño salvaje al niño prodigio" en Dávila, Paulí y Naya, Luis. La infancia en la historia. Espacios y representaciones. Donostia: Erein, pp. 761-775.

Kristeva, Julia. 1999 [1996]. Sentido y sinsentido de la rebeldía. Literatura y psicoanálisis. Santiago: Cuarto Propio, 368 p.

Lastra, Pedro. 1980. Conversaciones con Enrique Lihn. Santiago: Universitaria, edición de 2008, 190 pp.

Lihn, Enrique. 1989a. Diario de muerte. Santiago: Universitaria, 83 pp.

. 1989b. Album de toda especie de poemas. Barcelona: Lumen, 154 pp.

. 1997. El circo en llamas. Germán Marín (comp.) Santiago: LOM, $694 \mathrm{pp}$.

. 2006 [2005]. Una nota estridente. Santiago: Ediciones Universidad Diego Portales, $111 \mathrm{pp}$.

. 2007 [1963]. La pieza oscura. Santiago: Ediciones Universidad Diego Portales, $3^{\mathrm{a}}$ ed., $67 \mathrm{pp}$.

. 2008a [1966]. Poesía de paso. Santiago: Ediciones Universidad Diego Portales, $2^{\text {a }}$ edición, 65 pp.

. 2008b [1969]. La musiquilla de las pobres esferas. Santiago: Universitaria, $68 \mathrm{pp}$.

Llanos, Eduardo. 2005. "Hacia Enrique Lihn" en Noguerol Francisca (Coord.). Contra el canto de la goma de borrar: Asedios a Enrique Lihn. Sevilla: Universidad de Sevilla, pp. 45-59. Conferencia del 10 de junio de 2004 dictada en la Fundación Neruda.

Nómez, Naín. 2004. "La poesía de los cincuenta: Aproximaciones a una modernidad en disolución" en Taller de Letras 34, pp. 85-96. 2006. Antología critica de la poesía chilena. Tomo IV. Santiago: LOM, $656 \mathrm{pp}$.

O’Nell, Roberto. 2008. "Yo no es. Lectura de cierto soneto de Enrique Lihn" en Taller de Letras 42, pp. 43-56.

Ostria, Mauricio. 2005. "El espejo roto. Notas sobre la poética de Enrique Lihn", en Noguerol Francisca (Coord.), Contra el canto de la goma de borrar: Asedios a Enrique Lihn. Sevilla: Universidad de Sevilla, pp. 105-120.

Polanco, Jorge. 2004. La zona muda. Una aproximación filosófica a la poesía de Enrique Lihn. Santiago: RIL, 200 pp.

Sennet, Richard. 1980 [1977]. Narcisismo y cultura moderna. Barcelona: Kairós, 155 pp. 
Valdés, Adriana. 2008. Enrique Lihn. Vistas parciales. Santiago: Palinodia, $174 \mathrm{pp}$.

Villanueva, Alberto. 2004. "Decir lo que se está obligado a decir: acerca de la poesía de Enrique Lihn” en Hispamérica 99, pp. 21-39.

Zapata, Juan. 2008. "La narrativa de Enrique Lihn: expresión de un referente cultural complejo" en Taller de Letras 42, pp. 23-42. 